\title{
Medical abortions among university students in Ghana: implications for reproductive health education and management
}

This article was published in the following Dove Press journal: International Journal of Women's Health

\section{Nana Nimo Appiah- Agyekum}

Department of Public Administration and Health Services Management, University of Ghana, Legon, Accra Ghana, Ghana
Correspondence: Nana Nimo AppiahAgyekum

Department of Public Administration and Health Services Management, University of Ghana, UGBS, P O Box LG 78, Legon, Ghana

Tel +2332437482I8

Email nnappiah-agyekum@ug.edu.gh
Purpose: In Ghana, unsafe abortion is a major cause of maternal mortality. Even though pharmaceutical drugs seem to be a key means of unsafe abortion, a paucity of evidence exists on the issue among adolescents, students, and other groups at risk. This study therefore explores the abortion experiences of Ghanaian university students with particular reference to pharmaceutical drugs to fill the knowledge gap and enrich the evidence base for reproductive health education, policies, and interventions on abortions among students.

Patients and methods: Undergraduate students from the University of Ghana were randomly selected and interviewed. The interviews was recorded, transcribed, and analyzed thematically using the framework analysis.

Results: Students were aware of safe medical abortion services but were reluctant to use them because of cost, stigma, and proximity. Generally, medical abortions were more likely to be self-induced among students with misoprostol-based drugs administered orally or vaginally. However, students also used various over-the-counter drugs, contraceptives, and prescription drugs singly, in series, or in combinations to induce abortion. Yet students had relatively little knowledge on the inherent risks and long-term implications of unsafe medical abortions and were more likely to have repeat abortions through unsafe medical methods.

Conclusion: Students' knowledge and awareness of safe medical abortion avenues have not influenced their propensity to use them because of stigma, cost, and other factors. Rather, several methods of unsafe medical abortions are used increasingly with dire long-term effects on students. Serious knowledge gaps exist among students on the methods and risks of medical abortion. Consequently, there is an urgent need to revise current abortion management approaches and redirect attention toward reducing stigma and financial and social costs of safe abortion services, and increasing the proactive engagement, counseling, and management of medical abortions among students.

Keywords: unsafe abortion, Ghana, medical abortion, university students, misoprostol

\section{Introduction}

Medical abortion, also known as chemical or pharmaceutical abortion, ${ }^{1}$ is a type of nonsurgical abortion in which medication or pharmaceutical drugs are used to terminate a pregnancy usually in the first trimester. ${ }^{2,3}$ Of the several means of medical abortions that have been proposed, current evidence supports the use of the antiprogestogen mifepristone followed by a prostaglandin analog like misoprostol or gemeprost over regimens that use methotrexate followed by misoprostol or misoprostol or any other alternative alone. ${ }^{4-6}$ However, because a combination of mifepristone and misoprostol is substantially less expensive and does not require special transport 
or storage arrangements yet still remains as effective, in terms of high complete abortion rates and low continuing pregnancy rates, as any published alternative, ${ }^{5}$ it remains by far the most commonly used nonsurgical alternative to surgical termination of early intrauterine pregnancy. ${ }^{7,8}$ Aside being approved for clinical use for over a decade, it is also recommended for use by the World Health Organization (WHO) and other key global reproductive health bodies. ${ }^{9,10}$

In general, although medical abortions are themselves not unsafe, ${ }^{11}$ or associated with significant risks, their use becomes unsafe when improperly obtained or administered without proper prescription, supervision, and follow-ups or when people access incorrect information and medication. ${ }^{6,12,13}$ In Ghana's case, for instance, Wells et $\mathrm{al}^{14}$ report an increase in unsafe abortions done through wrongly administered pharmaceutical substances often with debilitating effects on parties involved. Though other reasons may be present, Aniteye et $\mathrm{al}^{15}$ further link the increase in the use of unsafe medical abortions in Ghana to the high levels of stigma associated with safe abortion services in general.

While majority of women who suffer complications or die from abortions in developing countries are under the age of 30 years, ${ }^{16}$ teenagers and women in their early 20 s are more likely to have an unsafe abortion using pharmaceutical substances in Ghana than other age groups. ${ }^{17,18}$ Importantly, the majority of young persons involved in this form of unsafe abortion in Ghana are students. ${ }^{19}$ This is in spite of comprehensive protocols and guidelines on abortions developed by the Ghanaian Ministry of Health in 2006 targeted at young persons and other groups at risk. These protocols and guidelines outline the components, qualifying criteria, authorized facilities and persons, processes, and scope of comprehensive abortion care. In addition, they also address the deficiencies of the Ghanaian criminal code [(Ghana, 1960), amended in 1985 (Ghana, 1985)] that criminalizes abortion and all persons involved in the act except in cases of rape, incest, or when the health of the mother is medically determined to be at risk.

Yet, relatively little evidence exists on the experiences, choices, methods, and availability of pharmaceutical substances used for self-induced abortions among young females. While a significant number of existing studies have focused on students' knowledge, perceptions, and awareness on abortion in general ${ }^{20}$ and other forms of unsafe abortion methods, ${ }^{19}$ Appiah-Agyekum et $\mathrm{al}^{21}$ suggest the urgent need to delve into the experiences and practices of use/abuse of pharmaceutical substances among students. Thus, this study aimed to highlight the abortion experiences of university students with particular reference to pharmaceutical drugs.
It also provides the much needed firsthand information on students' knowledge, awareness, acceptance, methods, and utilization of unsafe medical abortions practices and its implications for reproductive health education and management.

This study's contributions are valuable since it examines the experiences and methods of abortions among students in a nonhospital setting, unlike the majority of studies on unsafe abortions in Ghana and the subregion that use hospital-based data. ${ }^{22}$ It thus provides firsthand empirical evidence to shape contemporary discourse, interventions, and policies on abortions among students by both state and non-state actors.

\section{Patients and methods}

The study collected data through in-depth interviews held between April and August 2015 involving 32 randomly sampled female students from the main and city campuses of University of Ghana based on Yin' ${ }^{23}$ analytical sampling. In line with Leong and Austin, ${ }^{24}$ three research assistants were recruited and trained to assist in recruiting respondents and recording and transcribing interviews.

Drawing strength from Appiah-Agyekum, ${ }^{25}$ the data collection procedure was begun by announcing and posting notices at strategic locations on the university campuses on the nature, content, inclusion criteria, and use of the study and asking interested students to contact the research team. The inclusion criterion was that respondents must have ever had an abortion. Within 3 weeks of posting the notices, 41 students had volunteered to partake in the study. They were contacted, taken through and given copies of the information sheet and consent forms for the study, and given a week to decide and provide informed consent on their further participation in the study. After the 1 week period, 32 students gave written informed consent and nine students declined further participation in the study.

Participation in the study was voluntary and prospective respondents regardless of their choice to participate in the study or not were briefed on the purpose, use, and significance of the study. In addition to seeking consent from respondents, appropriate permissions were sought from the relevant university authorities. All respondent details and information provided were anonymized. The study was also reviewed and approved by the research and conference committee of the University of Ghana Business School and the Ethics Committee for the Humanities of the University of Ghana prior to data collection.

Interviews were held privately at lecture rooms, meeting rooms, and faculty offices usually at the close of lectures. 
They were also held at the convenience of respondents to allow them operate within their comfort zones. Interviews lasted between 45 and 80 minutes and were aided by an interview guide. Before analysis, interviews were recorded, transcribed, and later given to respondents to sign-off to allow them to review the transcribed data and confirm the accuracy and authenticity of the information attributed to them. ${ }^{26} \mathrm{~A}$ pre-testing of the interview guide was done prior to the actual data collection.

The data were analyzed qualitatively using the framework analysis approach outlined by Pope et al. ${ }^{27}$ Analysis began by gaining familiarity with the data. This was done through immersion in the raw data by listening to recordings, reading transcripts, and studying interview notes. Second, thematic frameworks were developed by the researcher by identifying and prioritizing key ideas and recurrent themes. The third stage was indexing and involved the refinement of broad themes into simple coherent brief summaries. This was followed by charting. Charting involved rearranging the data according to the appropriate part of the thematic framework under which they fell. Charts of emerging themes were drawn at this point by merging and redefining subthemes. Finally, mapping and interpretation were done by using the charts to define concepts, describe the nature of themes, create typologies, and find associations between themes.

Discussions of the themes were done within the context of relevant literature. Particular attention was also paid to the comments and answers to follow-up questions by respondents during the discussion.

\section{Results}

\section{Participant characteristics}

Participants were drawn from all years of study of the 4-year degree programs run by the University of Ghana. All respondents were aged $>18$ years. Majority of the participants were Christian (56\%) and were currently dating (59\%). Other characteristics of the participants are shown in Table 1.

\section{General results}

About half of the respondents (48\%) had undergone an abortion more than once with majority (59\%) of them having undergone an abortion before their 20th birthday and in their first trimester of pregnancy (90\%). A significant majority of participants (87\%) had also considered safe abortion services even though relatively few (53\%) had actually ever used them.

Generally, students described several unsafe abortion methods performed by unqualified and unskilled providers
Table I Characteristics of the participants

\begin{tabular}{ll}
\hline Participant characteristic & Frequency (\%) \\
\hline Age (years) & \\
I5-19 & $10(32)$ \\
$20-24$ & $18(56)$ \\
$25-29$ & $2(6)$ \\
$\geq 30$ & $2(6)$ \\
Year of study & \\
First & $8(25)$ \\
Second & $10(31)$ \\
Third & $8(25)$ \\
Final & $6(19)$ \\
Religion & \\
Christian & $18(56)$ \\
Muslim & $5(16)$ \\
Others & $3(9)$ \\
Not stated & $6(19)$ \\
Marital status & \\
Single & $9(28)$ \\
Married & $4(13)$ \\
Dating & $19(59)$ \\
Number of abortions & \\
One & $17(53)$ \\
More than one & $15(47)$ \\
Total & $32(100)$ \\
\hline
\end{tabular}

outside the legal framework of abortions in Ghana. Several participants reported combining different unsafe abortion methods either in series or simultaneously to enhance effectiveness or because one method did not work at all or did not complete the abortion. A common practice among respondents with repeat abortions was the use of methods they had used for previous abortion(s) except in cases where those methods had not worked or were not immediately available. Another common theme among respondents was the involvement of male partners in the decision to abort, choice and timing of abortion methods, financing of abortions, and provision of abortifacients.

\section{Pharmaceutical abortifacients/methods}

Pharmaceutical abortifacients especially misoprostol-based brands evolved as the most common means of abortion experienced by students who participated in the study. In addition, safe medical abortion services provided by blue star facilities (a network of private safe abortion and reproductive health care providers) were more popular among students than those provided by public health facilities in Ghana. Although participants showed high knowledge of the availability of safe medical abortion outlets, the utilization of the services provided by these outlets was not prominent in the experiences shared by the participants. Instead, experiences shared by students suggest that they were more content and 
comfortable obtaining and using pharmaceutical substances themselves instead of going to a safe medical abortion service provider as they believed that to be a cheaper and more discreet option.

...they will give you the same medabon which I can buy

in town for less than a third of their price without having to fill any forms or be embarrassed in front of people.

[19 years, level 200]

Furthermore, students who had used the services of blue star facilities in Ghana did not patronize them for subsequent abortions nor recommend their use to their peers because of the unfavorable proximity, stigma attached to persons seen entering or leaving the premises of safe abortion providers, acquired knowledge on administering the drugs, overbureaucratic administrative processes, waiting time, and cost of services.

...once they taught me how to use the drug, I didn't see the need to go there again to join the same queue and go through the same processes.... [21 years, level 400]

In addition to Medabon (Sun Pharmaceutical Industries Europe B.V., the Netherlands) (one pill of mifepristone and four pills of misoprostol) that had been approved by the Ghana Health Service for first trimester abortions, the use of misoprostol-only drugs, mainly Cytotec (Pharmacia Ltd, Morpeth, Northumberland, UK) for abortions was also common among students. Also, over-the-counter (OTC) drugs like Aspirin (Zydus Cadila, Gujarat, India) and Diclofenac (Blue Cross Laboratories Ltd, Mumbai, India) were used solely or in combination with alcoholic beverages, herbs, and roots while prescription drugs like metformin (Macleods Pharmaceuticals Ltd, Himachal Pradesh, India), Faverin (Mylan Laboratories SAS, Châtillon-sur-Chalaronne, France), or Paxil (GlaxoSmithKline plc, London, UK) were easily available and obtained illegally from both private and public health care facilities, pharmacies, and drug outlets for abortions. In general, price, recommendation from peers, success from prior use, length of gestation, and availability were the key factors influencing their use.

...these drugs are everywhere and once you are willing

to pay what they ask, you will get it without any hassle or

funny questions. [19 years, level 100]

Experiences shared by participants also show that pharmaceutical abortifacients were primarily administered orally or as suppositories or through both the means. Findings also show that pharmaceutical abortions were often self-induced through wrong administration and wrong dosages and combinations of OTC drugs, or prescription drugs. Several combinations of OTC drugs, prescription drugs, and/or contraceptives had also been used to induce abortions by students even though overdosing combinations of emergency contraceptive pills with painkillers were popular. Some participants had also induced abortions through the therapeutic effect of other pharmaceuticals meant for other health conditions. Arthotec (Searle Industrie, Evreux, France) and Oxaprost (Beta Laboratories, La Rioja - Argentina), which though contain misoprostol and diclofenac, are originally meant to treat arthritis and rheumatism, respectively, were common in this regard among students.

...my friend told me that Arthrotec, even though is used for arthritis would suffice for the abortion, I went to a pharmacy and simply told them I had been sent by my mother to buy it for her joint pains. [20 year old, level 200]

Majority of students reported a successful abortion on the first attempt using pharmaceutical abortifacients while some participants who were unsuccessful with the first attempt used a higher dosage of the same medicine, substituted the medicine, or combined it with other medicines in subsequent attempts which were successful. With the exception of severe abdominal pain, prolonged nausea, hemorrhage (excessive/copious bleeding), fatigue, and fever, no immediate or short-term adverse effects of using medications for abortion were reported.

\section{Discussion}

Findings by Shah and Ahman, ${ }^{28}$ Ahiadeke, ${ }^{29}$ and Sedgh $^{30}$ confirm that unsafe abortions involved incorrect administration of medications and were performed by unqualified and unskilled providers outside the legal framework of abortions. Especially among students, Ankomah et $\mathrm{al}^{31}$ confirm the likelihood of repeat abortions that may be attributable to the low contraceptive usage among students. ${ }^{25,32}$ In contrast to Banerjee et $\mathrm{al}^{33}$ who report the use of multiple sources of the same unsafe abortion method after previous unsuccessful attempts, findings suggest that students were unlikely to repeat an unsafe abortion method that had not provided the desired results within the expected time. In addition, findings draw attention to the combination of unsafe abortion methods either in series or simultaneously with significant potential risks. While similar high-risk unsafe abortion practices have been associated with young people, ${ }^{34}$ the prevalence of these practices among students, based on this study, seems to be associated more with the desire to catalyze or improve the efficacy of the abortion method rather than other factors like ignorance, ${ }^{35}$ poverty, ${ }^{36}$ and mitigation of perceived risks of complications. $^{37}$ 
In general, there has been a gradual shift from surgical abortions to pharmaceutical abortifacients ${ }^{38}$ attributable to advances in technology, market shifts, and related increased levels of access to pharmaceutical abortifacients. ${ }^{39,40}$ This seems to be the case in Ghana where findings from earlier studies by Appiah-Agyekum et $\mathrm{a}^{21}$ confirm that pharmaceutical abortifacients are the most preferred abortion methods among university students. This may however not be the case for all categories of the population as surgical abortions have been identified as the preferred abortion method for working women and married women in Ghana. ${ }^{29,41}$

Consistent with El-Adas, ${ }^{42}$ misoprostol-based brands are very popular among students who appeared relatively knowledgeable on how to access and use them for abortions. However, because the efficacy of misoprostol is associated with first trimester abortions, performed under skilled supervision, in combination with mifepristone or to aid other means of abortion, ${ }^{43,44}$ its unmonitored use and abuse by students especially outside the conditions above may expose them to significant risks. These may include uterine rupture, ${ }^{45}$ incomplete abortions ${ }^{46}$ and other high-risk contraindications that may lead to long-term reproductive health challenges with its attendant effects. ${ }^{47}$

Findings of unsafe use of common analgesics and other OTC drugs, either alone or in combination with emergency contraceptive pills or other substances to induce abortions by participants, are causing distress considering the ease with which these drugs could be obtained and abused. While generally the use of mild analgesics does not cause spontaneous abortion or pose any significant risk when used to reduce pain in induced abortions ${ }^{48}$ they may, when overdosed or wrongly administered for the main purpose of inducing abortions, increase the risk of preeclampsia and preterm birth in subsequent pregnancies. ${ }^{49}$ In the case of prescription drugs, even limited uncontrolled use may be addictive and may have serious physical and psychological effects ${ }^{50}$ on the students.

Pharmaceutical drugs in general may have severe consequences even to a toxic or lethal extent when improperly combined or used concurrently with other pharmacological substances or items with chemical properties.$^{51}$ Consequently, unsafe abortion performed through a combination of drugs exposes students to significant health risks. Findings from this study on the common use of arthritis medication by participants to gain the therapeutic benefit of abortions seem to be consistent with Watzer et $\mathrm{al}^{46}$ and show a growing trend in the use of pharmaceutical substances which may cause abortion as a side effect or contraindication among abortionseeking students.
Consistent with Patel and Desai, ${ }^{52}$ pharmaceutical abortifacients were mainly administered orally or vaginally or both. While findings of Paluku et $\mathrm{al}^{53}$ support that education and literacy levels have a significant influence on the choice and use of pharmaceutical abortifacients, other factors like price, ${ }^{54}$ success from prior use, ${ }^{55}$ length and timing of pregnancy, ${ }^{56}$ and availability ${ }^{57}$ were also key factors that influenced students' choice of pharmaceuticals. Safety and potential side effects, ${ }^{58}$ legal restrictions, ${ }^{59}$ and available information and support systems ${ }^{12}$ were however not supported by findings as factors influencing students' choice and utilization of pharmaceutical abortifacients even though these factors were found to be key determinants of choice of medical abortions in other studies.

\section{Implications for reproductive health education and management}

Generally, students seem to be knowledgeable and aware of pharmaceutical abortion services, abortifacients, processes, inherent risks, and associated effects. Yet, high stigma and social unacceptance of using abortion services, whether safe or not, implied that self-induced abortion methods were more acceptable to students than those that required assistance from skilled personnel. This by implication therefore suggests that the conventional practice of increasing the availability of safe abortion services may not necessarily translate into increased utilization of these services in the absence of a vibrant effort aimed at destigmatizing abortion services. Again, the legal restrictions that criminalize abortion and parties engaged in it seem to be having an unintended effect of increasing clandestine abortions especially as students strive to have undetected abortions.

In addition, this study draws the attention of reproductive health educators and practitioners that female decisions to abort are almost always carried out regardless of how it is performed, how much it costs, and how many times the abortion may be performed. Repeated attempts to terminate a pregnancy through one method or varying the preparation and administration of abortifacients to enhance efficacy show the desire and will of students to abort irrespective of repercussions; some of which may be long-term and immediately not manifested. This raises several important questions on the approaches and emphasis on the management of unsafe abortion practices among the youth and students especially.

As evidenced by this study, because majority of pharmaceutical abortions are performed in the first trimester where students may not show visible signs of pregnancy and may thus not be noted by reproductive health stakeholders, reactive measures at targeting pregnant mothers and 
abortion-seeking females may yield little returns. Meanwhile, stigma, embarrassment, and discomfort also restrict students from seeking assistance with their pregnancies or counseling on decisions to abort. Therefore, as an effective management strategy, focus must be shifted to proactive measures of providing open yet more private avenues for students using peer networks, private social media communication, anonymous counseling, and abortion information set-ups. Other mechanisms like 24 hour hotlines and web-based support services that have been successful in other countries may also be considered.

Also findings of repeat abortions especially done in teen years by students also raises key questions on the efficacy of interventions and the significant funding and attention that have consistently been placed on preventing teenage pregnancies among girls in school. Considering evidence from other studies suggesting teenage girls as a key group at risk of unsafe abortions and the increasing numbers of recorded abortions among students, equal if not more emphasis must rather be channeled to managing teenage abortions and developing specific informational material aimed at students than on the prevention of pregnancy.

Furthermore, the increased use of pharmaceutical abortions generally seems to be linked to the perception that it is a risk-free, convenient, and cheaper abortion method. While it may be less risky and carry less complications than other crude abortion methods, reproductive health stakeholders must drive home the point that it nonetheless has its own risks and associated complications. Particularly, by varying drugs, over-dosing, wrongly mixing or combining medications, and other unsafe practices, students seem to increase their risks of suffering reproductive health complications and infections and further reduce their chances of safe pregnancy and delivery later in life. These risks are exacerbated by the unregulated use of medications, lack of follow-ups, and prior pregnancy testing to determine the length of gestation and the self-induced nature of pharmaceutical abortions.

Considering the above, reproductive health policymakers and educators must generally enhance counseling and advisory services for populations at risk in addition to increasing initiatives to prevent abortions. While stiff punishments and legislations that criminalize abortions may achieve short-term success in preventing abortions, they have the long-run effect of forcing students to clandestinely opt for unsafe abortion practices. Practically, attention and educational efforts on managing unsafe abortions must shift immediately toward promoting safe sexual habits and contraceptive use among students rather than the usual emphasis on abstinence, which seems not to have had much influence on students.
The ease and freedom with which unsafe abortion services and medical abortifacients seem to be readily available for sale from peddlers, chemical shops, and unauthorized facilities has a positive impact on their acceptance, use, and referrals. Poor monitoring and regulation of the health sector as well as lax application of policies on safe abortion services seem to provide illegal abortion providers a field day to market and operate with dire consequences on their subjects. Mass education, provision of safe abortion hubs, and subsidizing safe abortion services around student campuses and settlements may well increase their access and propensity to use safe abortion services. Reproductive health policies and education must also throw more light on reducing abortion stigma and creating greater opportunities for dialog and interaction with students and other populations at risk on their decisions to abort as well as the available safe options.

Finally, experiences shared by participants also indicate a high level of involvement and support by their male partners in the decision to abort, choosing a method of abortion, funding the procedure as well as support throughout the process. Yet, reproductive health policies and education seem to overly focus on females without appropriately involving their partners. Targeting male partners in safe abortion initiatives may thus provide a lasting key to prevent abortion in the first place and swaying choices toward safe abortion services if that fails.

\section{Conclusion}

Even though there may be similarities in abortion decisions and experiences among the youth in general, this study supports Appiah-Agyekum et $\mathrm{al}^{21}$ that some striking differences exist in outcomes between youths of varying literacy and educational levels. Consequently, experiences of students on abortions in terms of their decisions, choice of method, and level of knowledge on abortions differ in illiterate and uneducated youths. For instance, while some studies ${ }^{42,60}$ report a high use of herbal abortifacients and quack doctor services among students, this study suggests that students are less likely to use those methods but are more likely to use misoprostol-based pills.

In addition, students seem to be knowledgeable of safe medical abortion services and likely effects of abortions even though choice of abortion methods was influenced by prior use, ease of access, cost, and referral from peers. While multiple abortions were common among participants, the use of multiple methods was also likely especially based on relative success and effects of previously used methods. In general, unsafe abortion services seemed to be more 
readily available and more utilized than safe services while self-induced abortion methods were more common than skilled assisted abortions.

In addition to providing an overview of the use of pharmaceutical abortifacients among students, the study provides deep experiential insights into methods and experiences of students with respect to medical abortions and the way forward in reshaping and managing unsafe use of pharmaceutical abortifacients. Apart from that, it provides the necessary information to guide evidence-based practice in sexual and reproductive health education and interventions among students.

\section{Limitations of the study}

The study may have some limitations in terms of generalizability because of the relatively small sample size. While the findings may be limited to University of Ghana students alone, it nonetheless provides a pathway for a larger and more detailed study on medical abortions and abortion methods used among students in general.

\section{Acknowledgments}

The author acknowledges Constance Sorkpor and Evans Datsomor for assisting with the data collection and transcription. This work was supported by the UGBS Research Grant.

\section{Disclosure}

The author reports no conflicts of interest in this work.

\section{References}

1. Riddle JM. Contraception and Abortion from the Ancient World to the Renaissance. Cambridge: Harvard University Press; 1994.

2. Louie KS, Chong E, Tsereteli T, Avagyan G, Vardanyan S, Winikoff B. The introduction of first trimester medical abortion in Armenia. Reprod Health Matters. 2014;22(Suppl 44):56-66.

3. Hodgson JE. Abortion and Sterilization: Medical and Social Aspects. Cambridge: Academic Press; 2014.

4. American College of Obstetricians and Gynecologists. Practice bulletin no. 143: medical management of first-trimester abortion. Obstet Gynecol. 2014;123(3):676-692.

5. Ashok PW, Penney GC, Flett GM, Templeton A. An effective regimen for early medical abortion: a report of 2000 consecutive cases. Hum Reprod. 1998;13(10):2962-2965.

6. Virk J, Zhang J, Olsen J. Medical abortion and the risk of subsequent adverse pregnancy outcomes. N Engl J Med. 2007;357(7):648-653.

7. Newhall EP, Winikoff B. Abortion with mifepristone and misoprostol: regimens, efficacy, acceptability and future directions. Am J Obstet Gynecol. 2000;183(2 Suppl):S44-S53.

8. Harper CC, Blanchard K, Grossman D, Henderson JT, Darney PD. Reducing maternal mortality due to elective abortion: Potential impact of misoprostol in low-resource settings. Int J Gynaecol Obstet. 2007; 98(1):66-69.

9. von Hertzen H, Honkanen H, Piaggio G, et al. WHO multinational study of three misoprostol regimens after mifepristone for early medical abortion. I: efficacy. BJOG. 2003;110(9):808-818.
10. Kapp N, Grossman D, Jackson E, Castleman L, Brahmi D. A research agenda for moving early medical pregnancy termination over the counter. BJOG. 2017;124(11):1646-1652.

11. Dahlbäck E, Maimbolwa M, Kasonka L, Bergström S, RansjöArvidson AB. Unsafe induced abortions among adolescent girls in Lusaka. Health Care Women Int. 2007;28(7):654-676.

12. van Look PF, Cottingham JC. Unsafe abortion: an avoidable tragedy. Best Pract Res Clin Obstet Gynaecol. 2002;16(2):205-220.

13. Berdzuli N, Pestvenidze E, Lomia N, Stray-Pedersen B. A maternal death from self-induced medical abortion: a call for action. Eur $J$ Contracept Reprod Health Care. 2017;22(5):393-395.

14. Wells E, Coeytaux F, Azasi E, et al. Evaluation of different models of access to misoprostol at the community level to improve maternal health outcomes in Ethiopia, Ghana, and Nigeria. Int J Gynaecol Obstet. 2016;133(3):261-265.

15. Aniteye P, O’Brien B, Mayhew SH. Stigmatized by association: challenges for abortion service providers in Ghana. BMC Health Serv Res. 2016;16(1):486.

16. WHO. Unsafe Abortion: Global and Regional Estimates of Incidence of Unsafe Abortion and Associated Mortality in 2003. Geneva: WHO; 2007.

17. Alan Guttmacher Institute. Abortion in Ghana. New York: Alan Guttmacher Institute; 2013.

18. Sundaram A, Juarez F, Bankole A, Singh S. Factors associated with abortion-seeking and obtaining a safe abortion in Ghana. Stud Fam Plann. 2012;43(4):273-286.

19. Appiah-Sekyere P. The perception of students on abortion: a survey of senior high schools in the Sunyani Municipality of Ghana. ABIBISEM $J$ Afr Cult Civiliz. 2013;4:12-18.

20. Ajayi A. University students and unsafe abortion practices: evidence from Nigeria. Paper presented at: Third ISA Forum of Sociology; Vienna, Austria; July 10-14, 2016; 2016.

21. Appiah-Agyekum NN, Sorkpor C, Ofori-Mensah S. Determinants of abortion decisions among Ghanaian university students. Int J Adolesc Med Health. 2015;27(1):79-84.

22. Biney AA. Exploring contraceptive knowledge and use among women experiencing induced abortion in the Greater Accra Region, Ghana. Afr J Reprod Health. 2011;15(1):37-46.

23. Yin RK. Case Study Research: Design and Methods. 4th ed. Vol. 5. Los Angeles: Sage Publications; 2009.

24. Leong FT, Austin JT. The Psychology Research Handbook: A Guide for Graduate Students and Research Assistants. Thousand Oaks, CA: SAGE Publications; 2005.

25. Appiah-Agyekum NN. Abortions in Ghana: experiences of university students. Health Sci J. 2014;8(4):531-540.

26. Seidman I. Interviewing as Qualitative Research: A Guide for Researchers in Education and the Social Sciences. New York: Teachers College Press; 2012.

27. Pope C, Ziebland S, Mays N. Qualitative research in health care. Analysing qualitative data. BMJ. 2000;320(7227):114-116.

28. Shah I, Ahman E. Unsafe abortion: global and regional incidence, trends, consequences, and challenges. J Obstet Gynaecol Can. 2009;31(12):1149-1158.

29. Ahiadeke C. Incidence of induced abortion in Southern Ghana. Int Fam Plan Perspect. 2001;27(2):96-108.

30. Sedgh G. Abortion in Ghana. Issues Brief. 2010;2:1.

31. Ankomah A, Aloo-Obunga C, Chu M, Manlagnit A. Unsafe abortions: methods used and characteristics of patients attending hospitals in Nairobi, Lima, and Manila. Health Care Women Int. 1997;18(1):43-53.

32. Lamptey P, Janowitz B, Smith JB, Klufio C. Abortion experience among obstetric patients at Korle-Bu Hospital, Accra, Ghana. J Biosoc Sci. 1985;17(2):195-203.

33. Banerjee SK, Andersen KL, Warvadekar J. Pathways and consequences of unsafe abortion: a comparison among women with complications after induced and spontaneous abortions in Madhya Pradesh, India. Int J Gynaecol Obstet. 2012;118(Suppl 2):S113-S120.

34. Olukoya AA, Kaya A, Ferguson BJ, Abouzahr C. Unsafe abortion in adolescents. Int J Gynaecol Obstet. 2001;75(2):137-147. 
35. Likwa RN, Biddlecom A, Ball H. Unsafe abortion in Zambia. Issues Brief. 2009;3:1-4.

36. Federation IPP. Death and Denial: Unsafe Abortion and Poverty. London, UK: IPPF; 2006.

37. Mukenge M. Testing Community Level Strategies to Reduce Unwanted Pregnancy and Unsafe Abortion in Suba District. Kenya: Findings from a Mid-term Evaluation; 2003.

38. Roberge LF. The future of abortion. Linacre $Q$. 1997;64(3):4-45.

39. Giannetti V. Pharmacists' beliefs about abortion and RU-486. $J$ Am Pharm Assoc (1996). 1996;36(12):698-703.

40. Osborn A. Russia proposes strict limits on abortions to boost population. BMJ. 2011;342.

41. Adanu RM, Ntumy MN, Tweneboah E. Profile of women with abortion complications in Ghana. Trop Doct. 2005;35(3):139-142.

42. El-Adas A. The Resolution of Unintended Pregnancy among Female Students at the University of Ghana, Legon. Legon: Regional Institute for Population Studies, University of Ghana; 2007.

43. Rocca C, Puri M, Blum M, Shrestha P, Grossman D, Harper C. Safety and effectiveness of access to medication abortion from pharmacy clinics in Nepal. Contraception. 2015;92(4):373.

44. Goldberg AB, Greenberg MB, Darney PD. Misoprostol and pregnancy. N Engl J Med. 2001;344(1):38-47.

45. Berghahn L, Christensen D, Droste S. Uterine rupture during secondtrimester abortion associated with misoprostol. Obstet Gynecol. 2001;98(5 Pt 2):976-977.

46. Watzer B, Lusthof KJ, Schweer H. Abortion after deliberate Arthrotec ${ }^{\circledR}$ addition to food. Mass spectrometric detection of diclofenac, misoprostol acid, and their urinary metabolites. Int $J$ Legal Med. 2015;129(4):759-769.

47. Grimes DA, Smith MS, Witham AD. Mifepristone and misoprostol versus dilation and evacuation for midtrimester abortion: a pilot randomised controlled trial. BJOG. 2004;111(2):148-153.

48. Livshits A, Machtinger R, David LB, Spira M, Moshe-Zahav A, Seidman DS. Ibuprofen and paracetamol for pain relief during medical abortion: a double-blind randomized controlled study. Fertil Steril. 2009;91(5):1877-1880.
49. Källén B, Reis M. Ongoing pharmacological management of chronic pain in pregnancy. Drugs. 2016;76(9):915-924.

50. Munk-Olsen T, Laursen TM, Pedersen CB, Lidegaard Ø, Mortensen PB. Induced first-trimester abortion and risk of mental disorder. $N$ Engl $J$ Med. 2011;364(4):332-339.

51. Zeliger H. Human Toxicology of Chemical Mixtures. New York: William Andrew; 2011.

52. Patel J, Desai T. Review on abortion-abortifacients to explore unethical issues. J Pharm Sci Biosci Res. 2012;2(5):213-218.

53. Paluku JL, Kalisoke S, Wandabwa J, Kiondo P. Knowledge and attitudes about induced abortions among female youths attending Naguru Teenage Information and Health Centre, Kampala, Uganda. J Public Health. 2013;5(4):178-185.

54. Mundigo AI. Determinants of unsafe induced abortion in developing countries. Unsafe Abort. 2006;51:51-71.

55. Misago C, Fonseca W. Determinants and Medical Characteristics of Induced Abortion among Poor Urban Women in North-East Brazil: Abortion in the Developing World. New Delhi: Vistaar Publications; London: Zed Books; 1999:217-227.

56. Sousa A, Lozano R, Gakidou E. Exploring the determinants of unsafe abortion: improving the evidence base in Mexico. Health Policy Plan. 2010;25(4):300-310.

57. Fernandez MM, Coeytaux F, Gomez Ponce de León R, Harrison DL. Assessing the global availability of misoprostol. Int J Gynecol Obstet. 2009;105(2):180-186.

58. Gracia CR, Sammel MD, Chittams J, Hummel AC, Shaunik A, Barnhart KT. Risk factors for spontaneous abortion in early symptomatic first-trimester pregnancies. Obstet Gynecol. 2005;106(5 Pt 1): 993-999.

59. Medoff MH. The determinants and impact of state abortion restrictions. Am J Econ Sociol. 2002;61(2):481-493.

60. Ma Q, Ono-Kihara M, Cong L, et al. Unintended pregnancy and its risk factors among university students in eastern China. Contraception. 2008;77(2):108-113.
International Journal of Women's Health

\section{Publish your work in this journal}

The International Journal of Women's Health is an international, peerreviewed open-access journal publishing original research, reports, editorials, reviews and commentaries on all aspects of women's healthcare including gynecology, obstetrics, and breast cancer. The manuscript management system is completely online and includes

\section{Dovepress}

a very quick and fair peer-review system, which is all easy to use. Visit http://www.dovepress.com/testimonials.php to read real quotes from published authors. 